\title{
Testing for the Association Between ACE DD (RS1799752) Polymorphism and the Metabolic Syndrome in Patients with Hypertension
}

\author{
Stanislav Alexandra Alina ${ }^{1,2}$ \\ ${ }^{1}$ Department of Biochemistry, Country Emergency Hospital, Clinical Laboratory Medical Analyzes, Giurgiu, Romania \\ ${ }^{2}$ Department of Genetics, Faculty of Biology, University of Bucharest, Bucharest, Romania
}

Email address:

SAalexy@yahoo.com

To cite this article:

Stanislav Alexandra Alina. Testing for the Association Between ACE DD (RS1799752) Polymorphism and the Metabolic Syndrome in Patients with Hypertension. Biochemistry and Molecular Biology. Vol. 5, No. 4, 2020, pp. 50-59. doi: 10.11648/j.bmb.20200504.12

Received: November 30, 2020; Accepted: December 7, 2020; Published: December 31, 2020

\begin{abstract}
High blood pressure (HBP) is a complex multifactorial condition which has a polygenic predisposition. The angiotensin-converting enzyme (ACE) is one of the candidate genes for HBP, and the ACE ID polymorphism with DD genotype presents a high risk for myocardial infarction, obesity (OB), stroke, type 1 diabetes mellitus (DM1), type 2 diabetes mellitus (DM2), diabetic nephropathy. The purpose of the study is to identify the high risk of developing MS in ACE DD gene (RS1799752) on the basis of clinical data, biochemical laboratory investigations, genotyping and sequencing of ACE gene in patients with HBP, by using the mathematical algorithm ANOVA One Way as a linear model, with the help of the MDR, Graph Pad Prism and MATLAB software. This study includes 68 subjects, selected from Giurgiu County Emergency Hospital based on clinical data, biochemical investigations, RFLP-PCR genotyping and Advanced NGx sequencing of the ACE gene with the DD genotype to identify the increased risk of developing metabolic syndrome (MS) in patients with hypertension. The results was taken by using as a linear model the mathematical algorithm ANOVA One Way using the programs MDR, Graph Pad Prism and MATLAB. In conclusion the ACE DD polymorphism is significantly associated with MS in patients with hypertension.
\end{abstract}

Keywords: ACE Gene, DD Genotype, Metabolic Syndrome, Hypertension

\section{Introduction}

Genetic dysfunction in hypertension (HBP) includes ACE gene, which is a susceptibility gene [8]. ACE is located on chromosome 17 and codifies 2 isoforms: the somatic form (sACE), with a molecular mass of $170 \mathrm{kDa}$, which is only expressed in the somatic tissue, and the testicular form (testis ACE, tACE), also called gACE (germinal ACE), with a smaller molecular mass, of $100 \mathrm{kDa}$, which, as its name suggests, is only expressed in the testicular tissue. These isoforms result from the activation of two alternative promoters. SACE expression is due to the activation of a promoter found in the 5'-region of the first exon (Spro) and it leads to the transcription of all the other exons. ACE gene is transcribed from a specific internal promoter, represented by a 91-pb fragment of intron 12 (Gpro): the resulting RNAm includes exons 13-26, while sACE RNAm corresponds to exons 1-26 (except exon 13, which undergoes splicing). The two isoforms differ by their function: SACE has two active sites (in the $\mathrm{N}$ and $\mathrm{C}$ terminuses), and tACE has one active site, an analog of the C-terminus portion of sACE. The serum ACE levels are considered stable, when they are repeatedly estimated in the same individual, but they significantly differ between individuals. In 1988 [4] and 1990 [17] researchers defined the presence of polymorphisms involving the presence of insertions (I) or the absence (deletions: D) of DNA fragments with a length of $287 \mathrm{pb}$. This type of polymorphism is located in intron 16 of the gene. The usual ID polymorphism is denoted as rs1799752. The ACE activity in the bearers of the DD polymorphic form is about twice as large as in individuals with genotype II. Subjects with genotype ID present intermediate levels, an indication of codominance. The I/D polymorphism has an incidence of about $47 \%$ of the variant observed in ACE levels. Recent studies indicate that 
I/D polymorphism is not limited to the serum ACE levels, but it is also detected through the ACE levels in other tissues. Initially, the method for the detection of ACE ID polymorphism was based on the RFLP-PCR test (restriction fragment legth polymorphism) [17]. ACE is a zinc metallopeptid which is widely distributed on the endothelial surface and in the endothelial cells. ACE inactively transforms a decapeptid, angiotensin I (Ang I or Ang 1-10) to an active octapeptid, angiotensin II, which is a strong vasoconstrictor (Ang II or Ang 1-8), which is the main active product of the renin-angiotensin system (RAS). RAS controls and regulates blood pressure and the blood volume in the body on a long term [16]. ACE polymorphism with phenotypes II and ID are associated with salt sensitive HBP. The mutations of ACE gene in the homozygous form ID produce angiotensin II, which is a risk factor for high blood pressure [6]. The critical intron 16 and of the I/D polymorphic variants on chromosome 17 are situated in the gene encoding the ACE peptide. Genotype DD has been frequently associated with a high concentration of serum circulating ACE, which leads to an increase in the reaction of conversion of inactive angiotensin $\mathrm{I}$ to active angiotensin II [26].

The Advanced NGx test (Next Gene test) uses the sequencing method, which allows several iterations (repeats) of the DNA sequence identifiction reaction, by which several genetic variations can be identified [15].

ANOVA One-WAY (ANOVA), also known as dispersion analysis or analysis of variance, proposes the comparison of more than two groups of subjects. It is recommended to use a larger number of steps of the independent variable in order to observe, with a wider degree of accuracy, the effect of the independent variable on the dependent variable [13], [20].

Graph Pad Prism 7 software is used in statistical analysis. This program provides the possibility to choose the decimal format used in reporting the P-value. Each analysis calculating P-value provides more options for the type of analysis [23].

The MATLAB program is used for creating artificial neural networks. These have been designed to help in engineering, economy and even medicine [11]. The human brain has been considered an extremely refined computer, whose thinking is like that of an electronic calculator [9]. ANN have been used in the rapid identification of people with high risk of MS [14]. The Redundant Network Routing Protocol (RNRP) is used in the diagnosis of essential hypertension (EHT) [19]. In the accuracy of the metabolic syndrome neural network models of discriminated analysis were used. The ROC analysis used the MATLAB software. The results showed that artificial neural networks have better performances, sensitivity and specificity in assessing MS than classical statistics models [22].

The purpose of the study is to identify the high risk of developing MS in ACE DD gene (RS1799752) on the basis of clinical data, biochemical laboratory investigations, genotyping and sequencing of ACE gene in patients with HBP, by using the mathematical algorithm ANOVA One Way as a linear model, with the help of the MDR, Graph Pad
Prism and MATLAB software.

\section{Materials and Methods}

\subsection{Study Setting and Desing}

\subsubsection{Clinical and Biochemical Data}

This study tested for the association between gene ACE, DEL/DEL (RS1799752) and the metabolic syndrome on a group of 68 subjects: 34 patients with HBP and 34 clinically healthy subjects forming the control group. The subjects were aged 20 to 100: 44 women and 24 men selected at Giurgiu County Emergency Hospital on the basis of their informal consent and a volunteer contract in the period 20142016. The following clinical data were recorded for these patients: BMI (body mass index), HBP and the family history, biochemical laboratory investigations: cholesterol, triglycerides, HDL-cholesterol, glucose, LDL-cholesterol, uric acid. The tests were performed with the BS-300 Mindray Chemistry analyzer, made in China. The work method used was spectrophotometry and it used blood serum as material to be analyzed [30].

\subsubsection{DNA Extraction}

The DNeasy Blood and Tissue kit from Qiagen was used for the DNA extraction [31]. The spectrophotometric determination of the purity and concentration of the isolated genomic DNA was performed with a NanoDrop. Before using the DNA extracted and purified in various molecular manipulations, its purity and integrity must be checked [25]. The RFLP-PCR technique was used in genotyping the ACE ID polymorphism. The RFLP-PCR protocol comprises: DNA extraction, PCR reaction, which took place in a Corbett thermocycler. The enzymatic digestion presents restriction fragments of $335 \mathrm{pb}$. Agarose gel electrophoresis (2\%) for the fragment separation. Staining was performed with ethidium bromide and it was followed by the amplycon analysis [5].

\subsubsection{ACE Gene Sequencing}

The sequencing of ACE gene was performed by Advanced NGx test. This is a genetic test presenting a combination of nutrigenetics tests, which provide scientifically validated information on: the genetic variations which define the necessary amount of nutrients for healthy adults; genetic variations associated with numerous metabolic risks, and for which nutritional management solutions exist; genetic variations causing certain metabolic diseases and rare genetic diseases; genetic variations of interest for the nutritional management of physically active people. It uses DNA, it is performed on a Ion Torrent machine and it includes 400 genetic variations with a number of 99 genes [15].

\subsubsection{Data Analysis}

The results were statistically processed through the ANOVA OneWay linear model $(p<0.0001)$, using MDR version 3.0.2 to calculate OR, ANOVA, Hardy-Weinberg Law [27, 12], Graph Pad Prism 7 version 7.03 [28], MATLAB R2009b version 7.9 .0529 [29]. Values $<0.05$ were 
considered statistically significant [23].

\subsection{Ethical Consideration}

This study was conducted from 20.01.2014-19.01.2015 and 20.01.2015-19.01.2016 as part of a volunteer activity at at Giurgiu County Emergency Hospital (Volunteer Contract no 2/20.01.2014 and contract no 2/20.01.2015 subject to art. 13 (5) of Law no 677/2001).

\section{Results}

It was 34 patients diagnosed with hypertension were included in the study. The clinical evaluation of HBP comprised the following parameters: age, sex, BMI, HBP, family history (the non-hereditary form predominated, while the hereditary form occurred in three families with parents diagnosed with HBP). In respect of age and sex, it was noted that: 22 patients were women $(64.70 \%)$ and 12 were men (35.29\%). Their ages went from 21 to 100 . In the age group 21-30 there were 2 female patients $(9.09 \%)$ and 0 male patients $(0 \%)$; in the age group 31-40 there were 3 female patients $(13.63 \%)$ and 1 male patient $(9.09 \%)$; in the age group 41-50 there was one female patient (4.54\%) and 2 male patients $(18.18 \%)$; in the age group 51-60 there were 6 female patients $(27.2 \%)$ and 4 male patients $(36.36 \%)$; in the age goup 61-70 there were 3 female patients (13.63\%) and 2 male patients (18.18\%); in the age group $71-80$ there were 5 female patients $(22.72 \%)$ and 1 male patient $(9.09 \%)$; in the age group 81-90 there were 2 female patients $(9.09 \%)$ and 2 male patients $(18.18 \%)$ and in the age group $91-100$ there were 0 female patients $(0 \%)$ and 1 male patient $(9.09 \%)$ (Figure 1).

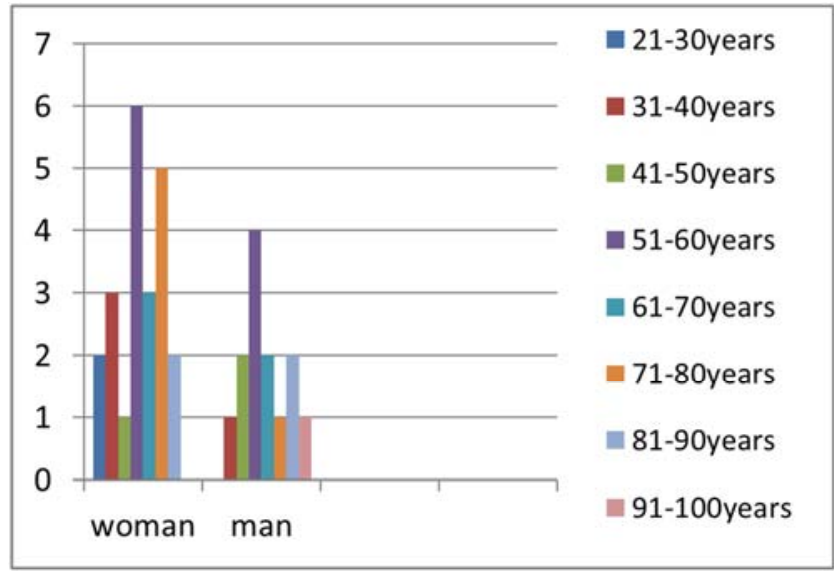

Figure 1. Percentile distribution of HBP according to age and sex.

The examination of Figure 1 reveals that the highest proportion of the HBP patients under investigation concerned the age group 51-60 in female patients. The biochemical laboratory investigations included the following parameters: cholesterol, triglycerides, HDL-C, LDL-C, glucose, uric acid. The high concentrations of cholesterol, LDL, triglycerides, glucose and uric acid, and the low concentrations of HDL are suggestive of a risk of hypertension event. Age and sex constitute the basic criterion in assessing hypertension. It follows that metabolic syndrome is present by reason of high concentrations of glucose, triglycerides and low concentrations of LDL-cholesterol. In ACE gene genotyping by RFLP-PCR technique, the frequency with which the MS characteristics were detected in the hypertension group are: high concentrations of glucose, triglycerides, LDLcholesterol, uric acid, hypertension, BMI and low concentrations of HDL. According to the Hardy-Weinberg equilibrium condition, it results that ACE DD genotype $(\mathrm{p}=0,0003)$, with $\mathrm{OR}=3.99$, where $\mathrm{OR}>1$ presents a high risk of developing $\mathrm{MS}$, and genotype II with $\mathrm{OR}=0.27$, has a protective role for MS (Figure 2).

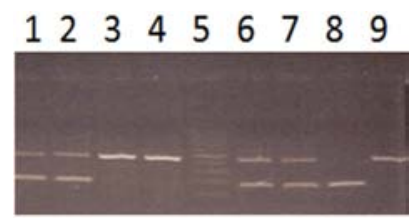

Figure 2. Agarose gel in RFLP-PCR presenting the ID polymorphism of ACE gene. Lines 1, 2, 6, 7: ACE ID genotype; Lines 3, 4, 9: ACE DD genotype; Line 8: ACE II homozygous genotype; Line 5: weight marker (100pb Ladder Fermentas).

Following the identification by sequencing by the Advanced NGx test of the ACE gene in the Metabolic Syndrome, the interaction between environmental factors and genes in the realization of personalized nutrition resulted. The study conducted on a group of 34 HBP patients aged between 21 and 100, of whom 22 women and 12 men, identified the ACE gene and its association with metabolisms in MS. The muscular function and the body weight were associated with ACE gene. It was noted that the predominant genotypes were the homzygous and the heterozygous ones. The patients presented high rates of cholesterol, triglycerides, LDL-cholesterol, BMI, glucose, uric acid, systolic and diastolic blood pressure, and low levels of LDL-cholesterol, all of which being associated with cardiovascular diseases, diabetes, obesity, which can increase the risk of metabolic syndrome. ACE gene, along with its markers, presents a high risk of developing metabolic syndrome. ACE gene was present in 33 patients with DD homozygous dominant genotype and in 1 patient with ID heterozygous genotype. MDR 3.0.2 statistical program was used on a group of 34 patients diagnosed with hypertension. The response variable is the high and low risk to develop metabolic syndrome, high blood pressure. The predictive variables are: diagnosis, age, sex, blood pressure and the variations of ACE DD gene. Depending on age and sex (22 women and 12 men), ACE Del/Del gene (RS1799752) presents the dominant homozygotes HD (2)=33 patients and the recessive homozygotes $\operatorname{HR}(0)=1$ patient. 


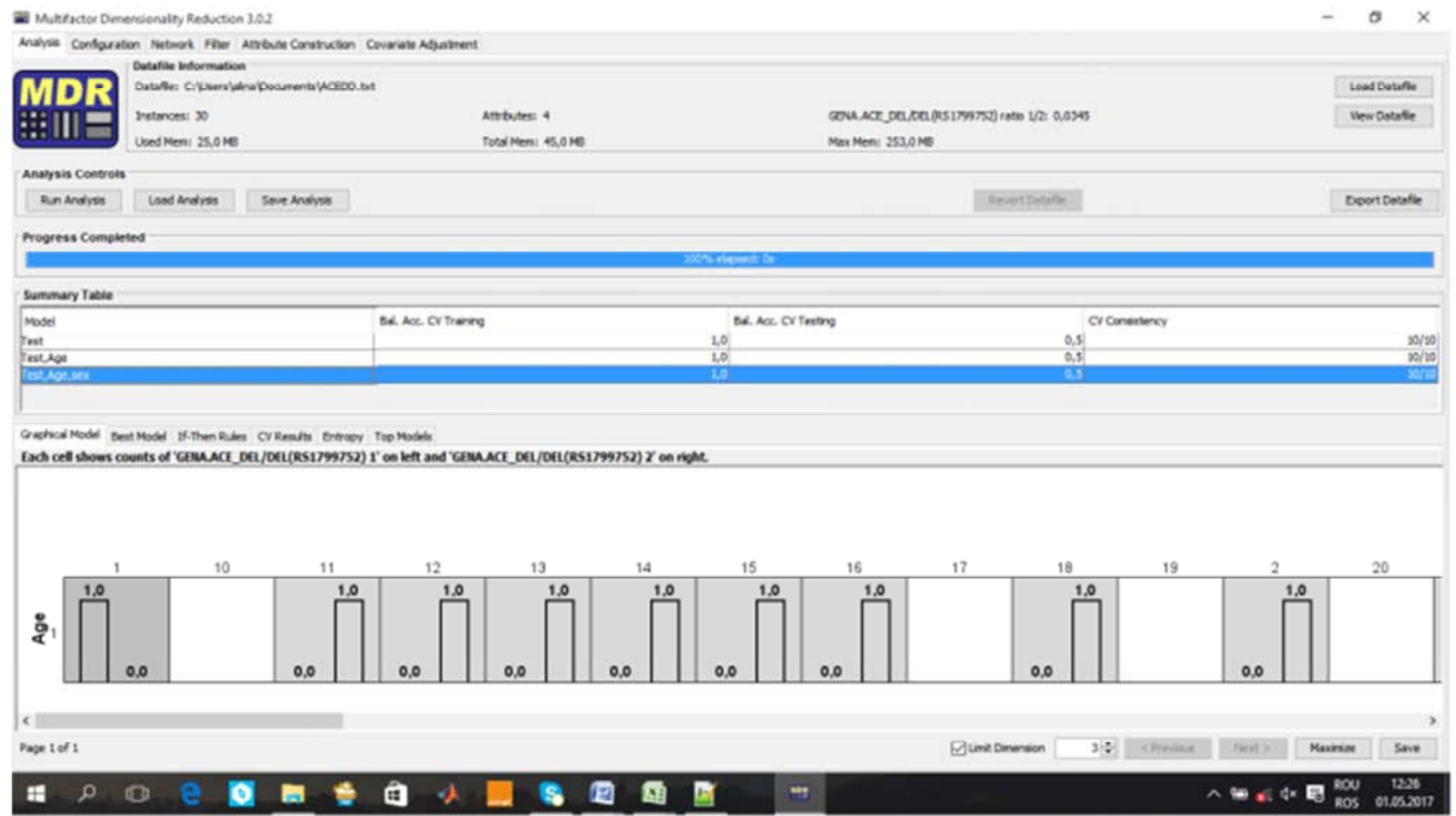

(a)

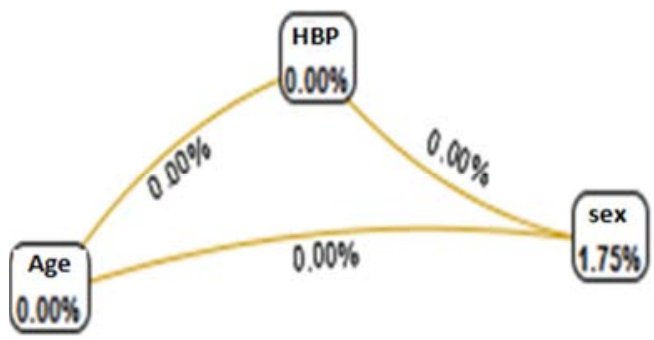

(b)

Figure 3. (a) Graphic interaction model for MS, HBP. (b) Interaction map for MS, HBP.

Figures $3 \mathrm{~A}$ and $3 \mathrm{~B}$ present the relation between sex, BP and age, and how they can influence the other parameters. Blood pressure increases with age and, in terms of sex, it occurs more frequently in men than in women among young people and middle-aged adults. It follows that age and sex can influence biochemical and genetic parameters. There may be differences between females and males and age differences between young and old people, regardless of gender, in terms of disease occurence (Test: normal, MS and HBP). From the statistical performance data measurements by MDR software, where pvalue test $<0.0001$, age $<0.0001$, sex $<0.0001$, $\mathrm{BP}=<0.0001$ and ACE DD gene $<0.0001$, it results that all clinical, laboratory and genetic parameters are significantly associated with MS in the HBP group ( $<<0.0001)$.

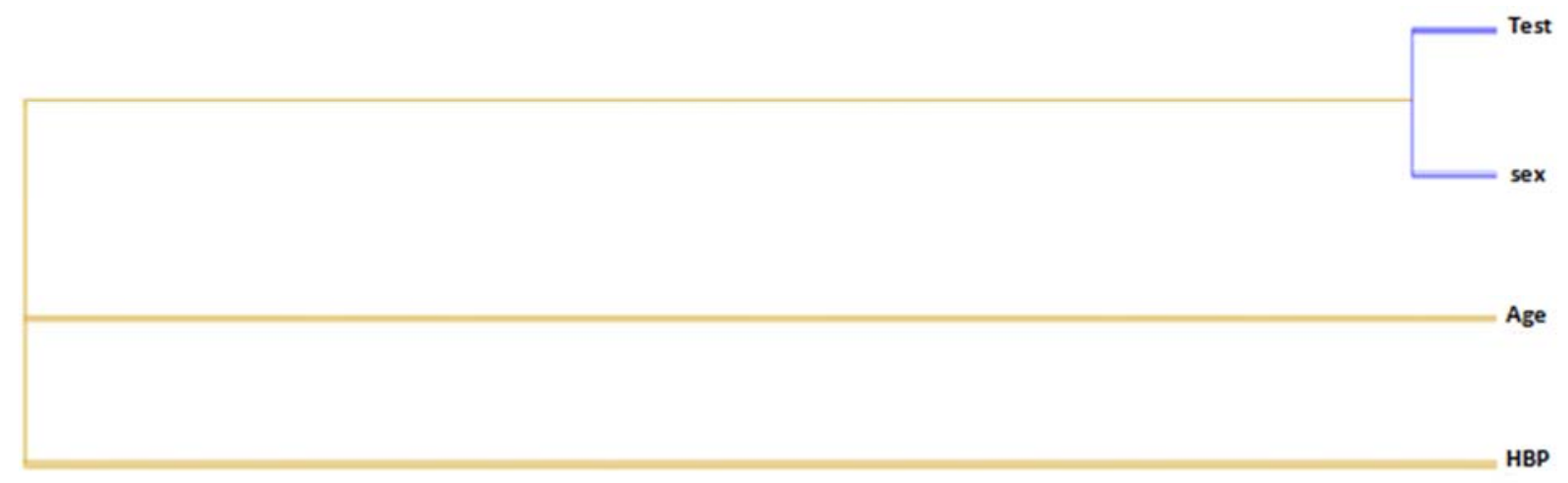


a Mutiscter Dimemionsity Reduction 10.2

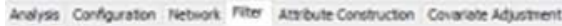

Fimer selection

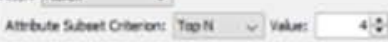

Finer obsens.

verestiogions 10 :

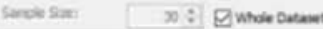

nimer centroits

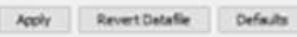

Progrexs Complated

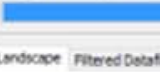

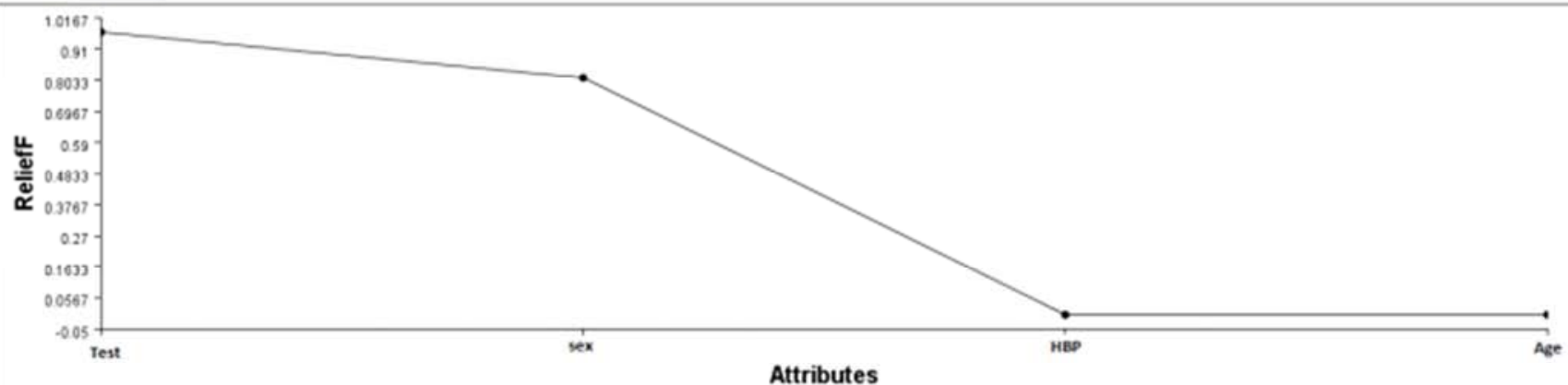

Attributes

(b)

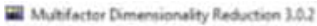

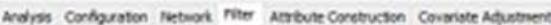
nither selection

then: $x$

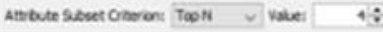

nimer ostoess

Gevales

Niner Controls

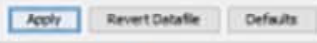

Progrewe Completed

Endiceser mitred oosats

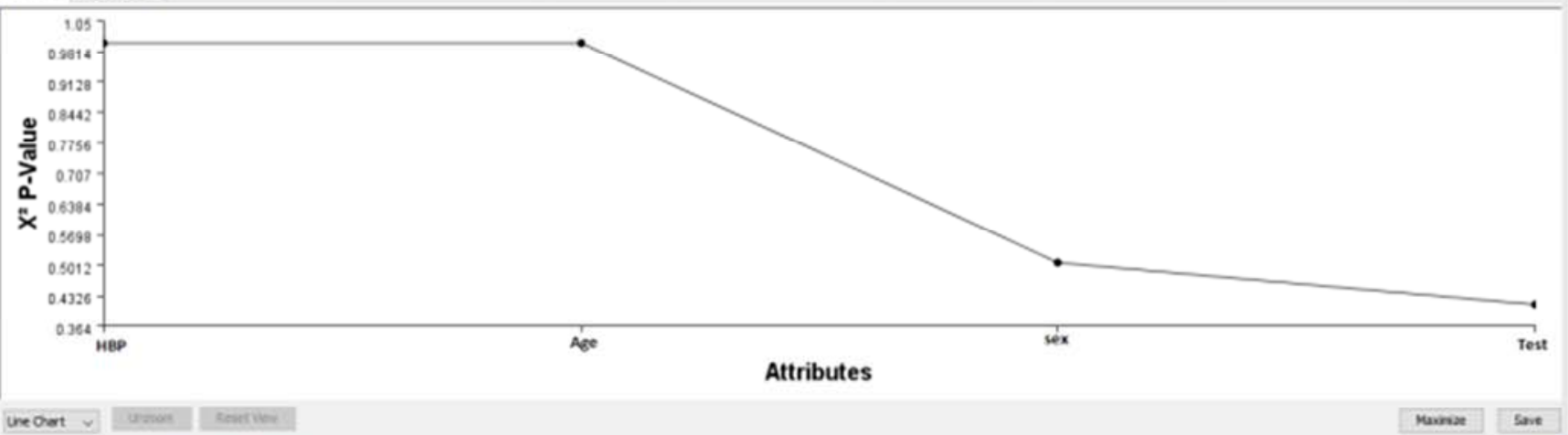

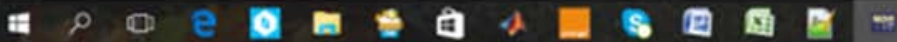




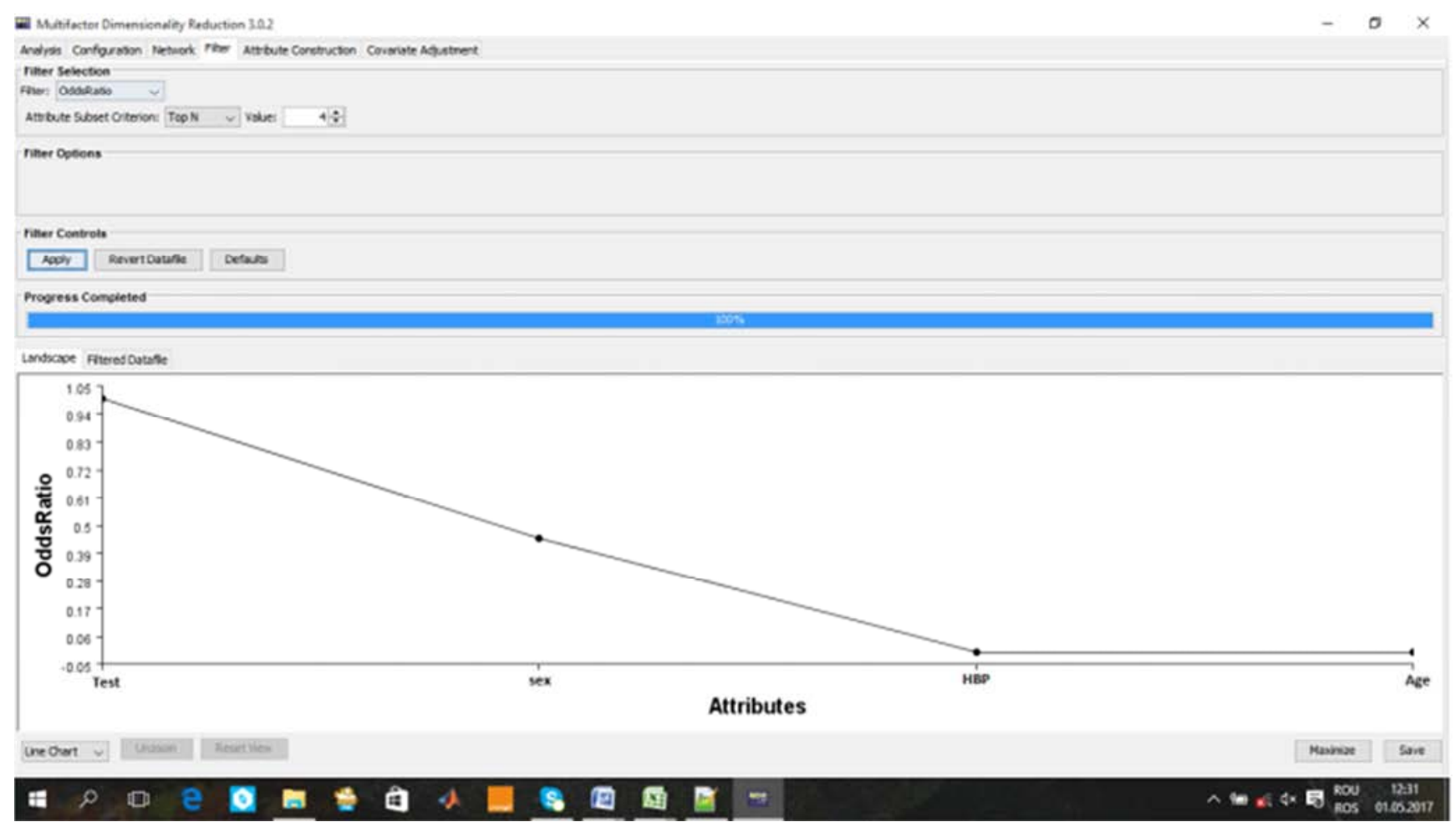

(d)

Figure 4. Data processing by MDR software evaluated by (a) dendogram obtained by calculating MDR, (b) ReliefF, (c) ValP, (d) OR.

From the analysis by MDR software using ReliefF, $\mathrm{X}^{2} \mathrm{P}-$ value (Hardy-Weinberg equilibrium) and Odds Ratio as filter, it results that the values for BP, age, sex, test, ACE DD gene, were significanlty higher in the group of patients, ReliefF $=0.96667 ; \quad \mathrm{X} 2 \quad \mathrm{P}$-value $=0.414003 \quad(\mathrm{p}<0.0001)$, $\mathrm{OR}=1.05$, where $\mathrm{OR}>1$, resulting in a high risk of developing metabolic syndrome in the HBP group (Figure 4). MDR software is a particular non-parameter genetic model, in that no real parameter is estimated. A cluster was determined by dendogram (Neibergoing method) based on the association between genes and environment (test, age, sex). It results that sex and age influence clinical data, laboratory and genetic investigations (Figure 5).

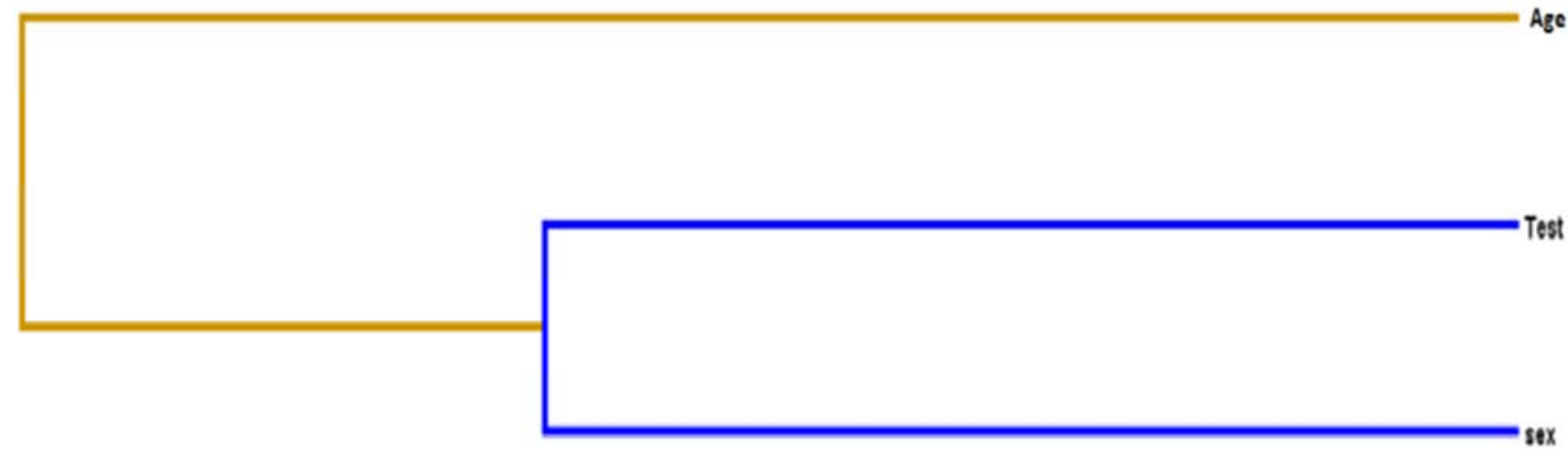

Figure 5. Cluster by dendogram produced by MDR software.

The Graph Pad Prism 7.0.3 software and MATLAB $\mathrm{R} 2009 \mathrm{~b}$ produced the same results. The results for ACE gene, DEL/DEL (RS1799752), were: BMI $(p<0.0001)$ is very significantly associated with $M S$, glucose $(p=0.1343)$, triglycerides $(\mathrm{p}=0.1589)$ are not significantly associated with metabolic syndrome, HDL $(p=0.0055)$ is very significantly associated, cholesterol $(\mathrm{p}=0.0014)$ is highly significantly associated, LDL $(\mathrm{p}=0.0014)$ and uric acid $(\mathrm{p}=0.0041)$ are very significantly associated and HBP $(\mathrm{p}<0.0001)$ is very significanlty associated with metabolic syndrome $(\mathrm{p}<0.05)$. It results that the BMI, HDL, cholesterol, LDL, uric acid and HBP are very significantly associated with MS, therefore ACE rs1799752 is associated with MS. ACE gene is statistically highly singnificantly associated with MS through the 2 bioinformatics software (Figure 6, Figure 7). 

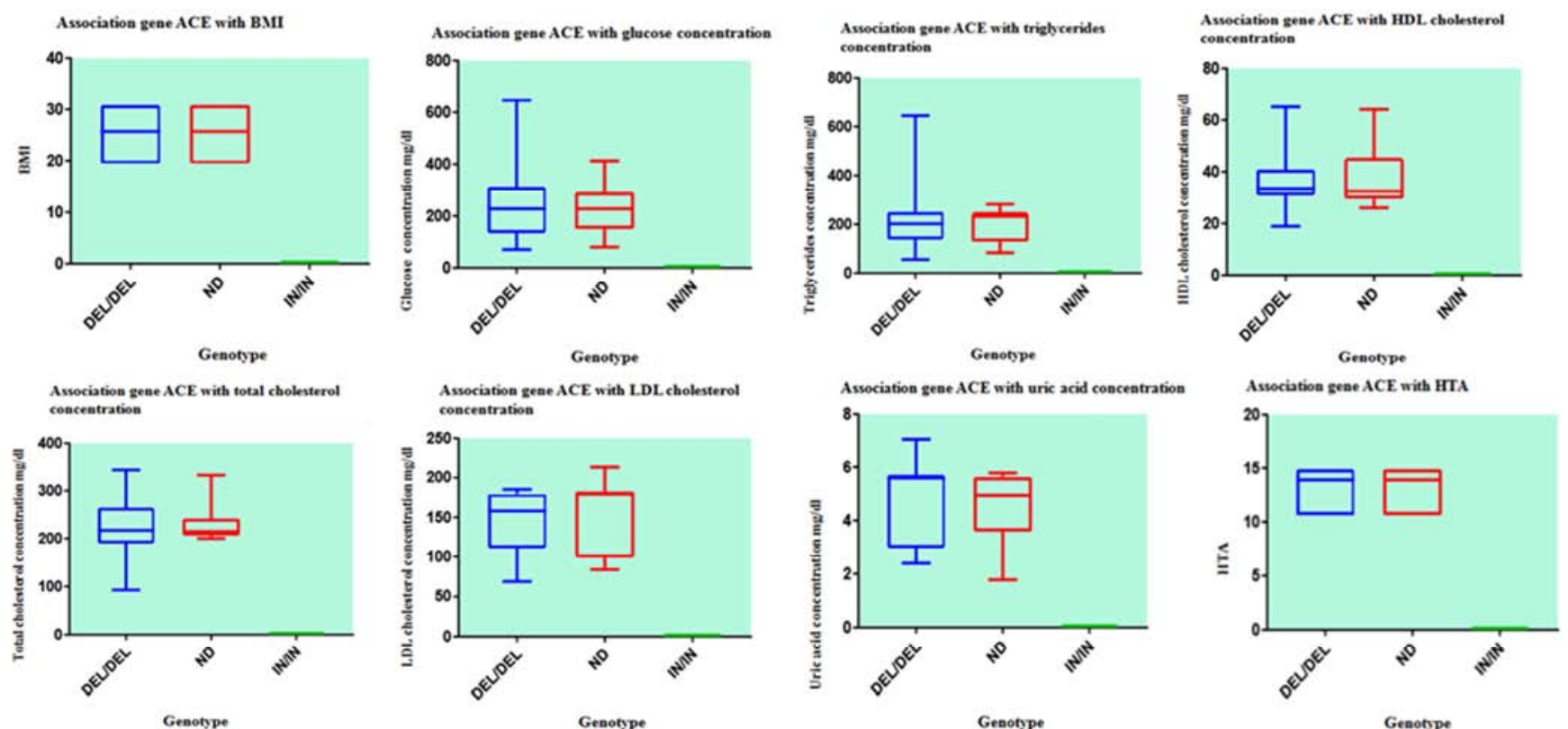

Figure 6. Gene ACE DEL/DEL, ND, IN/IN, gene ACE_DEL/DEL (RS1799752) processed by Graph Pad Prism 7 on the basis of the following parameters: $B M I$, glucose, triglycerides, $H D L$-cholesterol, total cholesterol, $L D L$-cholesterol, uric acid and HBP.

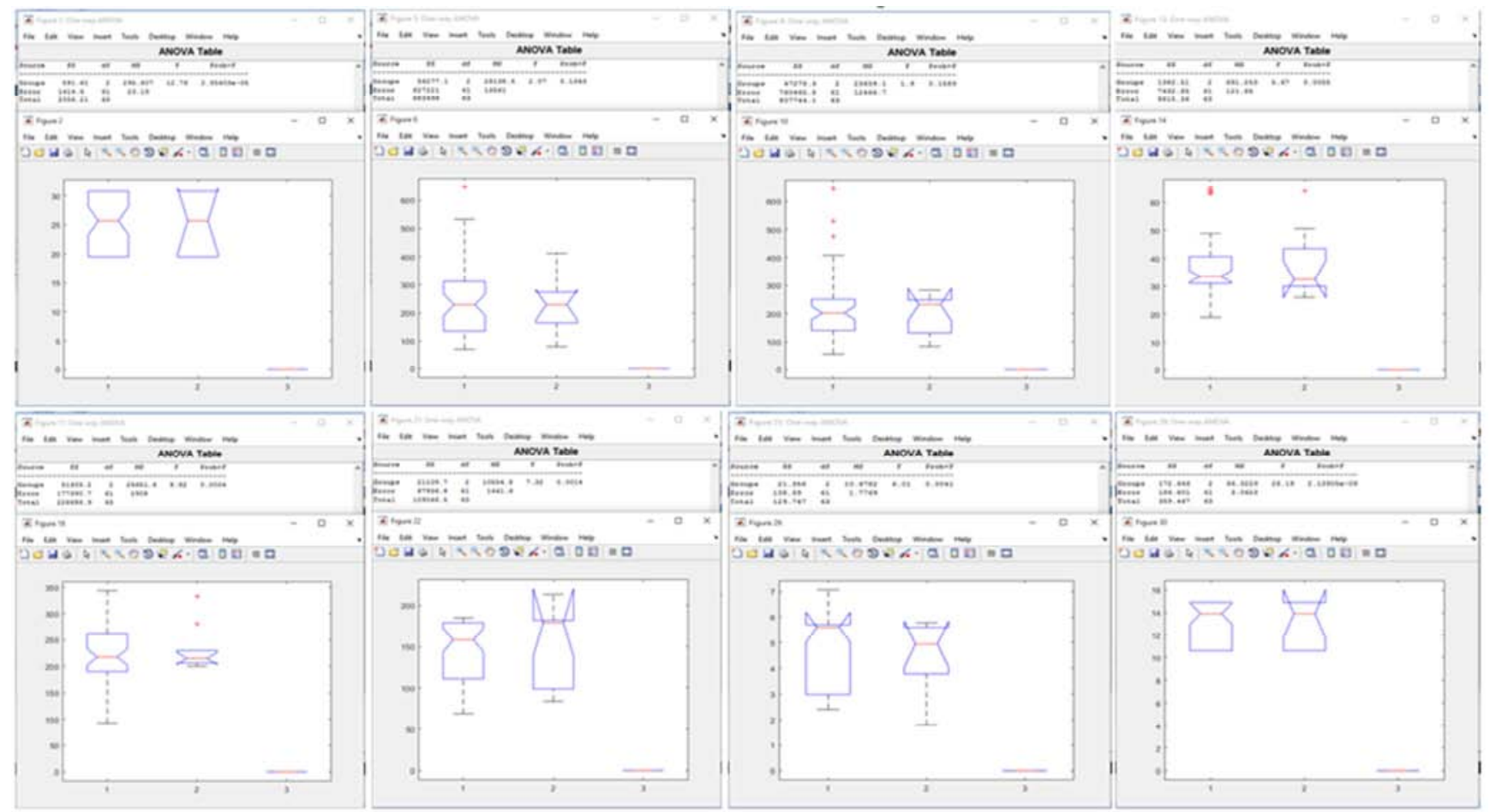

Figure 7. Gene ACE DEL/DEL (RS1799752) by the MATLAB R2009b program on the basis of the following parameters: BMI, glucose, triglycerides, HDLcholesterol, total cholesterol, LDL-cholesterol, uric acid and HBP.

The control group is composed of 34 subjects considered clinically healthy. It included the following parameters: age, sex, BMI, HBP, family history. The biochemical laboratory investigations comprised the following parameters: cholesterol, triglycerides, HDL-cholesterol, glucose, LDLcholesterol, uric acid, which ranged within normal limits. According to age and sex, there were 22 female subjects and 12 male subjects, aged 21 to 100 . The genotyping of ACE gene through RFLP-PCR and the identification through Advanced NGx in the control group by MDR 3.0.2, Graph Pad Prism 7.0.3 and MATLAB R2009b, resulted in the DD genotype of ACE gene with ReliefF $=0.0067$; X2 Pvalue $=1.05 \quad(\mathrm{p}<0.0001), \quad \mathrm{OR}=0.1161, \quad$ where $\quad \mathrm{OR}>1$, indicating a role of protection against developing metabolic syndrome in the control group. The results obtained after the evaluation of the clinical and paraclinical data of the 68 inpatients divided into 2 groups (hypertension and control) confirmed the following: in group 1, made up of patients 
diagnosed with high blood pressure, the risk of developing metabolic syndrome is present in both sexes. Metabolic syndrome can easily be used in clinical practice, when it is evaluated on the basis of age and sex criteria, since it provides evidence of a potential cardiovascular risk. The interpretation of the (biochemical) laboratory investigations through ANOVA One Way mathematical method is based on: low HDL-cholesterol, high concentrations of blood sugar, triglycerides, LDL and uric acid which, confirm the risk of developing metabolic syndrome. The following parameters are added to these data: age, BMI, HBP which, by their high concentrations, confirm the risk of developing metabolic syndrome in the HBP group. Using the RFLPPCR technique, it results that ACE ID polymorphism with DD genotype presents a high risk of developing MS, while genotype II is a protection factor. Following the statistical analysis performed by using MDR software version 3.0.2, it was noted that the Hardy-Weinberg Law and the Odds Ration calculation was as follows: in the HBP group $p=1.05$, $\mathrm{OR}=1.26$ so it results that $\mathrm{p}$ is statistically significantly higher than $\mathrm{p}<0.0001, \mathrm{OR}>1$, so it results a high risk of developing MS; while the control group has $p=1.05$, $\mathrm{OR}=0.1161$, where $\mathrm{OR}<1$, so it results it has a protection role. MDR was used for the detection and characterization of the gene-gene and gene-environment interaction, with effect on the risk of developing common complex multifactorial diseases. It was used for the analysis of the interaction between 8 genetic and environment factors in the 68-subject group. In using the Advanced NGx test it was noted that the dominant homzygous form and the heterozygous form for the muscular function and body weight were associated with ACE DD gene (high concentrations of cholesterol, triglycerides, LDLcholesterol, uric acid, BMI, blood sugar, systolic and diastolic blood pressure and low levels of HDL-cholesterol). These are associated with cardiovascular diseases, diabetes, obesity and they can increase the risk of metabolic syndrome. It has been observed that the ACE gene along with its DD genetic variation is associated with nutrition in healthy adults, lipid, carbohydrate, behavioral metabolism have been associated with increased risk of developing metabolic syndrome. After sequencing, the clinical data (age, sex, BMI, BP), biochemical laboratory data (glucose, triglycerides, HDL, cholesterol, LDL, uric acid) and the genetic variation of ACE gene were correlated and they are associated with a high risk of developing metabolic syndrome.

\section{Discussion}

In 1996, Staessen and collaborators noted that, at $\mathrm{OR}=1.10(95 \% \mathrm{CI}=0.95-1.27)$, there is a high risk, of $10 \%$, of HBP in genotype DD [21]. The ACE ID polymorphism with DD genotype is associated with low HDL-cholesterol. In myocardial infarction (MI) the ACE ID polymorphism of ACE enzyme is associated with an increase in total cholestrol and LDL-cholesterol. It presents an association with BMI and blood lipids, so that the BMI corresponding to overweight occurs more frequently in patients with ACE ID genotype rather than with ACE DD genotype, and allele $\mathrm{D}$ of gene ACE is present in abdominal obesity. Genotype $\mathrm{DD}$ of $\mathrm{AC}$ gene is associated with high levels of total cholesterol, VLDL, LDL, TG and low HDL. In homozygous and heterozygous of ACE gene an interrelational association with environment factors such as systolic and diastolic blood pressure, smoking and diabetes mellitus was identified. The increase in age leads to a decrease in the number of patients with ACE II genotype and an increase in the number of those with ACE DD. ACE DD genotype occurs more frequently in males than in females, and ACE ID does not present a clear association with blood lipids and BMI. The ACE ID polymorphism plays an important role in the human hemodynamic regulation and it is associated with multifactorial diseases [2]. In 2009, Settin and collaborators reported a significantly higher BMI in bearers of allele D. It was demonstrated that subjects with DD genotype lose less body fat than bearers of I alle. Rs4340 and rs 1799752 are in the same 288-bp ID. Rs1799752 is a 2-bp IN/DEL which surrounds the 3 nucleotides of the 288-bp IN/DEL of rs4340. The ACE ID polymorphism influences the concentration and activity of serum ACE. Bearers of D allele have an higher average ACE serum concentration than bearers of I allele [3]. It was demonstrated that the allelic ACE variation is responsible for $47 \%$ of the serum ACE variance. In particular, D allele and DD genotype are associated with high levels of ACE and a higher risk of adverse cardiovascular events and lesions of terminal organs. The correlation of DD genotype and the high propensity for developing hypertension can be attributed to the increased conversion of Ang II, suggesting that in these homozygotes, the high levels of ACE modulate the RAS function [1]. The literature suggests that individuals with ACE DD (or GG) and ID (or AG) genotypes, as compared with the bearers of II (or AA) genotype, seem to be more vulnerable to the impact of excess adiposity, especially at adult age [24]. Obesity is defined by WHO as a global chronic epidemic due to excess accumulation of fat mass [10]. These findings can have important implications for the reduction of obesity-related hypertension in children and adults [24]. ACE gene (Rs1799752) with DD genotype was associated with higher levels of ACE and an activity four times higher than in genotype II, beside higher levels of blood pressure, obesity and high cardiovascular risk. Research suggests that the ID polymorphism is an aggressive factor for the development of renal lesions in type 1 diabetes mellitus [18]. ACE2 is mainly expressed by epithelial cells of the lungs, gut, kidneys and blood vessels. This may explain the high incidence of pneumonia and bronchitis in patients with severe COVID-19 infection. A recent study showed that ACE2 is also highly expressed on the mucosa of the oral cavity, providing the virus with easy access to a new sensitive host [7]. 


\section{Conclusion}

The ACE gene with DD genotype (RS1799752) presents a high risk of developing metabolic syndrome on the basis of the clinical data, biochemical and genetic laboratory investigations, and on the basis of RFL-PCR genotyping and sequencing by Advanced NGx applying MDR, Graph Pad and Matlab bioinformatics software on the HBP group. In conclusion the ACE DD polymorphism is significantly associated with MS in patients with hypertension.

\section{Acknowledgements}

I wish to express my gratitude to all those people who provided qualified guidance and effective support in carrying out this study: Professor Tatiana Vassu-Dimov PhD, scientific coordinator of my doctoral thesis, Mr. Dănut Gheorghe Cimponeriu, Professor at the Genetics Department of the Faculty of Biology, Bucharest University, Ms. Natalia Cucu Professor at the Genetics Department of the Faculty of Biology, Bucharest University, Ms. Ileana Stoica Professor at the Genetics Department of the Faculty of Biology, Bucharest University, Ms. Alexandra Simon Gruiță Professor at the Genetics Department of the Faculty of Biology, Bucharest University for allowing me to use the facilities of the Human Genetics Laboratory in conducting the genetic tests, and Dr. Popescu-Guinea Gelu, head of the Diabetes, Nutrition and Metabolic Diseases Section within the Internal Diseases Department of Giurgiu County Emergency Hospital, who indicated to me the clinical criteria for the selection of patients with metabolic syndrome, obesity and diabetes mellitus, whose biological samples were investigated in the Clinical Bacteriology Laboratory of Giurgiu County Emergency Hospital under the guidance of Dr. Matefi Felicia, head of the laboratory, and Dr. Mihai Petre, Manager of Giurgiu County Emergency Hospital, who authorized my internship on a volunteer basis (Volunteering Contract no. $2 / 20.01 .2014)$, thus enabling me to gather the biological material included in this study.

\section{References}

[1] A. R. Ajala, S. S. Almeida, M. Rangel, Z. Palomino, M. Wany L. Strufaldi, R. F. Puccini, R. C. Araujo, D. E. Casarini, M. C. P. Franco, Association of $A C E$ Gene Insertion/Deletion Polymorphism With Birth Weight, Blood Pressure Levels, and ACE Activity in Healthy Children, American Journal of Hypertension, Volume 25, Issue 7, July 2012, https://doi.org/10.1038/ajh.2012.50, Published: 01 July 2012, https://academic.oup.com/ajh/article/25/7/827/2282142, pp. $827-832$.

[2] N. Arkhipova, E. Popova, L. Grigorieva, 2014, The angiotension converting enzyme (ACE) gene I/D polymorphism in different ethnic groups of geriatric age living in the Far North 2014., SciRes. Vol. 6, Nr. 5., 426-431 (2014) Health, 2014, pp. 426- 431.

[3] F. G. Bouwman, Jolanda M. A. Boer, Sandra Imholz, P. Wang, W. M. Monique Verschuren, M. E. T. Dollé, E. C. M.
Mariman, Gender-specific genetic associations of polymorphisms in ACE, AKR1C2, FTO and MMP2 with weight gain over a 10-year period, Genes \& Nutrition, volume 9, Article number: 434 (2014) 5 https://link.springer.com/article/10.1007/s12263-014-0434-2, Springer Link, FPublished: 17 October 2014, pp. 2, 4.

[4] F. Cambien, F. Alhenc-Gelas, B. Herbeth, J. L. Andre, R. Rakotovao, M. F. Gonzales, J. Allegrini, C. Bloch, Familial resemblance of plasma angiotensin-convertining enzyme level: the Nancy study. Am. J. Hum. Genet. 43: 1988. 1988. pp. 774780 .

[5] S. Chanda, Molecular Markers: RFLP AFLP RAPD SNP Procedure barefoot farmbooks, Barefoot farmbooks, www.farmbooks.blogspot.com, March 22, 2018, pp. 1.

[6] D., Cimponeriu D., Suport de curs Genetica umană, Facultatea de Biologie, Universitatea din București, 2013, pp. 1, 2, 3, 4

[7] E. Ciaglia, COVID-19 Infection and Circulating ACE2 Levels Protective Role in Women and Children, Front. Pediatr., 23 April 2020, https://doi.org/10.3389/fped.2020.00206, https://www.frontiersin.org/people/u/83692, pp. 2-5

[8] M. Covic, Genomica hipertensiunii arteriale - o nouă cale pentru descifrarea patogeniei moleculare a bolii, Viața medicală, ARHIVA | 2012 | AUGUST | NUMARUL 30 (1176), pp. 1.

[9] R. Cârmaciu, C. Th. Niculescu, L. Torsan, Anatomia și fiziologia omului îndrumător pentru elevi, Editura Didactică și Pedagogică, București, 1983, pp. 125.

[10] C. Dumitrache, Endocrinologie... de la A la Z-dicţionar enciclopedic Editura Naţional, Bucureşti, 2008, pp. 158, 159, $160,257-258,380,382,461,526,527,530,534,534-535$, 714-715.

[11] D. D. Farcaș, 1979, Calculatorul electronic și gândirea umană, Editura Albatros București, 1979, pp. 238.

[12] L. W. Hahn, M. D. Ritchie, J. H. Moore, Multifactor Dimensionality Reduction software detecting gene-gene and gene-environment interactions, Bioinformatics, Vol. 19, No 3, 2003, pp. 376-382.

[13] D. E. Hinkle, W. Wiersma, S. G. Jurs, 1994, Applied statistics for the behavioral sciences (3rd.). Boston, USA: Houghton Mifflin Company., 1994, pp. 1, 3, 4.

[14] C. Hui, X. Shenghua, R. Xuan, 2014, Evaluating the Risk of Metabolic Syndrome Based on an Artificial Intelligence Model, Hindawi Publishing Corporation Abstract and Applied Analysis Volume 2014, Article ID 207268, Hindawi, pp. 12.

[15] M. Niculescu, Advanced Nutrigenomics LLC, 2016., pp. 2, $\mathrm{http}: / /$ www.advancednutrigenomics.com/welcome/

[16] P. Ramaraj, S. P. Kessler, C. Colmenares, G. C. Sen, 1998, Selective restoration of male fertility in mice lacking angiotensin-converting enzymes by sperm-specific expression of the testicular isozyme. J. Clin. Invest. 102:, 1998, pp. 371378 .

[17] B. Riga, C. Hubert, F. Alhenc-Gelas, F. Cambien, P. Corvol, F. Soubrier, An insertion/deletion polymorphism in the angiotensin I-converting enzyme gene accounting for half the variance of serum enzyme levels. J. Clin. Invest. 86, 1990, pp. 1343-1346. 
[18] L. Salazar-Sanchez, J. J. Madrigal-Sanchez, P. GonzalezMartinez, E. Paredes, L. Vera-Gamboa, N. P. Ruz, N. Valadez-Gonzalez, Open access peer-reviewed chapter, ACE I/D (Rs1799752), MTHFR C677T (Rs1801133), and CCR5 D32 (Rs333) Genes and their Association with Hypertension and Diabetic Nephropathy in Urban Areas of Costa Rica, Nicaragua, and Mexico, Submitted: October 22nd 2015, Reviewed: June 7th 2016Published: September 14th 2016, DOI: 10.5772/64548, Home Essential Hypertension, https://www.intechopen.com/books/update-on-essentialhypertension/ace-i-d-rs1799752-mthfr-c677t-rs1801133-andccr5-d32-rs333-genes-and-their-association-with-hyperten, pp. 2,3 .

[19] R. Samant, S. Rao, Evaluation of Artificial Neural Networks in Prediction of Esential Hypertension, International Journal of Computer Applications 0975-8887, Volume 81, Nr. 12, November 2013, pp. 34, 35, 37.

[20] F. Sava, 2002, Pagina de statistică socială., http://statisticasociala.tripod.com., pag. 1, 12.

[21] F. A. Saved-Tabatabaei, B. A. Oostra, A. Isaacs, CM. Van Duijn, J. C. Witteman, ACE polymorphisms, Review Circulation Research, 2006: 98: 2006, pp. 1123-1133.

[22] M. Sedehi, Y. Mehrabi, A. Kazemnejad, F. Hadaegh, Comparation of Artificial Neural Network, Logistic Regression and Discriminant Analysis Methods in Prediction of Metabolic Syndrome, Iranian Journal of Endocrinology\&Metabolism, Vol. 11, No. 6 March 2010, pp. 1.

[23] A. Segonds-Pichon, Version 2017-02, Introduction to Statistics with Graph Pad Prism, This manual is 2008-17, Babraham Bioinformatics, http://cdn.graphpad.com/docs/prism/6/Prism-6-StatisticsGuide.pdf, pp. 8, 9, 41, 42 .
[24] C. Sun, A-L. Ponsonby, J. B. Carlin, M. Bui, C. G. Magnussen, T. L. Burns, T. Lehtimaki, N. H. Wardrop, M. Juonala, J. S. A. Viikari, A. J. Venn, O. T. Raitakari, T. Dwyer, Childhood adiposity, adult adiposity, and the $A C E$ gene insertion/deletion polymorphism: evidence of geneenvironment interaction effects on adult blood pressure and hypertension status in adulthood, J Hypertens. available in PMC 2019 May 1. J Hypertens. 2018 Nov; 36 (11): 21682176. doi: 10.1097/HJH.0000000000001816, PMCID: PMC6452450,

https://www.ncbi.nlm.nih.gov/pmc/articles/PMC6452450/, pp. 2168-2176.

[25] T. Vassu-Dimov, O. Csutak, I. Stoica, F. Muşat, Genetica microorganismelor şi inginerie genetică microbiană-Note de curs şi tehnici de laborator., Editura Petrion, Bucureşti, 2001, pp. 76-82.

[26] E. Villard, L. Tiret, S. Visvikis, R. Rakotovao, F. Cambien, F. Soubrier, Identification of new polymorphisms of the angiotensin I-converting enzyme (ACE) gene, and study of their relationship to plasma ACE levels by two-QTL segregation-linkage analysis, Am J Hum Genet. 1996 Jun; 58 (6), pp. 1268-1278.

[27] MDR software versiunea 3.0.2 (20.02.2013 15: 27, versiune3.0.2 http://sourceforge.net/projects $/ \mathrm{mdr} /$

[28] Graph Pad Prism 7 versiunea 7.03 www.graphpad.com

[29] Software MATLAB R2009b versiunea 7.9.0529 www.mathworks.com/patents

[30] www.mindray.com.

[31] http://www.ebiotrade.com/buyf/productsf/qiagen/dneasy tissu e_system.htm., DNeasy Blood\& Tissue Handbook, Qiagen, July 2006 